\title{
Gender characteristics of self-concept among students-athletes
}

\author{
Yulia Popova $^{1 *}$, Valery Petkov ${ }^{1}$, Anna Balyk $^{2}$, Ksenia Bulakh $^{2}$, Irina Glushchenko ${ }^{2}$ \\ ${ }^{1}$ Kuban State University, 350040, Krasnodar, Russia \\ ${ }^{2}$ Nevinnomyssk State Humanitarian -Technical Institute, 357108, Nevinnomyssk, Russia
}

\begin{abstract}
Self-concept is the base for personal activity demonstration, stimulation, goal-setting and achievements. Athletes' Self-concept study helps to estimate significant factors and characteristics. They are important from the point of view of sports activity effectiveness. The article presents the results of Self-concept study among students-athletes. The results reflect partial content similarity of girls' and boys' Self-concept. It is in identification through professional roles and Self-concept differences. They are demonstrated in more vivid desire of girls to realize selfactualization. Self-concept gender characteristics study among studentsathletes helps to explain the necessity to create gender-specific conditions of athletes' sportsmanship development.
\end{abstract}

\section{Introduction}

The importance of understanding psychological regularities of psyche functioning among athletes is evident. It conditions the interest of coaches, athletes, sports society in psychological models and algorithms of sports activity. The training loads increase is not enough for the best sports results achievement and an optimal athletes' personal potential revelation, especially at the stage of sportsmanship formation [1-4]. It is necessary to understand the conditions and factors of athletes' personality self-concept formation. It is a special personal formation, connected with self-consciousness, reflexion. It demonstrates the essence characteristics of self-understanding, the specificity of interconnection between individual and environmental characteristics. It conditions all demonstrations of a personality's activity, the unique character of his choices and style of activity. It plays great role in self-regulation of an athlete at the initial stages of sportsmanship formation. Studying the characteristics of self-concept helps to reveal significant and important directions of an optimal psychological potential revelation [5-8,9]. The main instrument of this potential revelation is inner psychic powers of athletes, self-determination and selfunderstanding. Because of the kind of sport specificity, there are special demands claimed on personal structure and its dynamics, connected with the ability to stand super- loads and regulate own state on the way to super-important aim achievement. Psychological price of such kind of activity is high, in this connection regulating, dynamic parameters of athletes' self-concept revelation, self-consciousness peculiarities form an important direction of the research. At the same time, the objective of understanding the importance of factors and conditions of athletes' self-concept development can be considered from the position of gender approach. It helps to estimate the presence of gender specificity absence in self-

* Corresponding author: jeis@ mail.ru 
concept development. It should be taken into account while creating conditions for athletes' sportsmanship development at a higher educational establishment.

\section{Materials and methods}

Students of Kuban State University (Krasnodar, Russia) took part in studying gender characteristics of Self-concept among students-athletes during 2018-2019. In general sampling formed 140 people (78 boys and 62 girls at the age of 17-19). The following methods were used in the research: the methodology of a personal semantic differential by O.L. Kustova, test of 20 statements by M. Kun and T. Mac-Partlend for self-attitude study, gender-role questionnaire by S. Bem, E. Shostrom questionnaire for personality's selfactualization study.

In order to estimate the image of oneself according to the methodology of a personal semantic differential by O.L. Kustova and gender-role positions according to S. Bem questionnaire, after calculating the frequency of notions appearance, we ranged the results according to the categories. The material of M. Kun and T. Mac-Partlend questionnaire for self-attitude study was handled by means of content-analysis. For self-actualization estimation according to E. Shostrom questionnaire we calculated the average for a group results according to each scale. For the validity of differences determination between the subgroups of boys and girls we used Mann-Whitney U test (при $p \leq 0,05$ ).

\section{Results and discussion}

Analysis of studying real images of oneself (O.L. Kustova methodology) helps to state, that boys define such qualities as (in decreasing order of importance): physicality, liberation, own opinion, reliability, love for children, power of a personality, confidence, kindness, erudition, courage. The least defined qualities of real self-images were the following: gentleness, hope for other people, security, orientation toward the opinion of other people, weakness, tenderness, lack of means, directness, fussiness, politeness, intuitiveness. Girls define the following qualities in themselves (in decreasing order of importance): love for children, aspiration for freedom, reliability, physicality, activity, kindness, own opinion presence, power of a personality, quick-wittedness, the ability to get on the right side of somebody. In a real self-image the following qualities were less defined among the girls: flexibility, hope for other people, fussiness, security, directness, love for animals, aspiration for stability, hope for intuition, image thinking, high social status.

In contrast to the girls for the boys important qualities of self-image were the following: confidence, liberation, erudition, courage.

In contrast to the boys, important female characteristics of self-image are the following: freedom, quick-wittedness, presentability, the ability to arouse trust. The least significant characteristics of self-image among boys are the following: jealousy, emotionality, cultural sensitivity. The least significant characteristics of self-image among girls are the following: image thinking, high social status, love for animals. Statistically these differences are significant, which is proved by Mann-Whitney correlation coefficient $\left(\mathrm{U}_{\mathrm{emp}}=1350\right)$.

In accordance with the received results we come to the following conclusion: there are differences in real self-images realization among boys and girls. These differences are vivid both among significant distinct qualities and among less significant ones.

Gender-role characteristics of a personality analysis (S. Bem questionnaire) helped to define balanced combination in the structure of a personality and in the behavior of students-athletes masculine and feminine traits, both among boys and girls. According to the frequency of the choice the following qualities prevail among boys: diligence, 
politeness, scrupulosity, will power, readiness to help, honesty, power, friendliness, sense of humor, masculinity, reliability. Among girls these qualities are the following: power of a personality, honesty, delicacy, sense of humor, readiness to help, kindheartedness, decency, friendliness, the ability to understand other person, femininity, thoroughness. Substantially revealed characteristics show androgyny of students-athletes. At the same time, there are statistically valid differences between girls and boys in the preference of the presented characteristics $\left(\mathrm{U}_{\mathrm{emp}}=639\right)$.

Personality's self-actualization index (E. Shostrom questionnaire) among girls according to "Orientation in time", "Need for cognition" and "Autonomy" and "Autosympathy" scales is 67\%; according to "Values", "Creativity" and "Selfunderstanding" scales 60\%; according to "Flexibility in communication" scale $57 \%$; "Sociability"- 50\%; according to "Spontaneity" scale $47 \%$ and according to "View of the nature of a person" scale $27 \%$. Among boys the average index according to "Selfunderstanding" scale is $60 \%$; according to "Orientation in time", "Values", "Need for cognition", "Creativity", "Autonomy", "Flexibility in communication" scales is 53\%; according to "View of the nature of a person", "Autosympathy", "Sociability" scales 47\%; and according to "Spontaneity" scale $-33 \%$. Statistically valid differences were revealed in terms of "View of the nature of a person" index $\left(U_{\text {emp }}=29\right)$, which is higher among boys, than among girls. In general the indices of self-actualization are higher among girls, than among boys. It shows that for girls the values of self-actualizing personality are more significant. The leading peculiarities of self-actualization among boys and girls differ. Among girls they are connected with a definite orientation toward the present moment of life, the need for cognition, autonomy, well-realized and positive Self-concept. Boys, first of all, connect self-actualization with sensitivity in terms of own needs in other aspects their self-actualization is similar to the revealed self-actualization of girls, but it is less distinct.

Content-analysis of self-descriptions according to "Who am I?" test by M. Kun and T. Mac-Partlend helped to reveal the following hierarchy of categories among boys: "profession" (287 references), "positive personal peculiarities" (271 references), "socialcultural roles" (250 references), "emotionality" (122 references), "optimism" (96 references), "love" (75 references), "appearance" (74 references), "erudition" (59 references), "hobbies" (55 references). According to "family roles", "interpersonal roles", "real-habitual functioning" and "communication" categories we define 45 references each, "negative characteristics" - 40 references and "attitude to labor"- 35 references. Among girls the following hierarchy of categories was revealed: "positive personal characteristics" (264 references), "profession" (144 references), "social-cultural roles" (138 references), "optimism" (118 references), "emotionality" (112 references), "appearance" (81 references), "negative characteristics" (80 references), "hobbies" (65 references), "family roles" (60 references), "erudition" (58 references), "interpersonal roles" (50 references), "real-habitual functioning" (25 references), "communication" (25 references), "attitude to labor" (25 references), "love" (5 references).

As a result of the analysis we come to the following conclusion: in self-attitude of boys the most important qualities are the following: sports professionalism -1 rank, positive personal characteristics -2 rank and social-cultural roles -3 rank. The least significant characteristics of self-attitude for boys are the following: attitude to labor -15 rank and the presence of negative characteristics - 14 rank. At the same time, girls defined the same categories of self-attitude, but for them the most important are the following categories: positive personal peculiarities -1 rank, profession -2 rank and social-cultural roles -3 rank. The least defined qualities of self-attitude among girls were the following: love and random characteristics (goddess, dishonourable person, just a person and others). We come to the conclusion that this group of respondents realizes the importance of professional- 
sports self-realization, as the main element of self-concept, but they have difficulties in realizing the ways of its achievement. It is proved by self-actualization results.

\section{Conclusions}

We can form the notion of self-concept characteristics of students-athletes and its gender specificity. Among the most distinct characteristics of self-concept of boys are the following: confidence and own opinion presence, positive attitude to oneself, courage, single-mindedness, uniqueness, power. Also the distinctive feature of self-concept among boys is self-understanding intensity. It proves boys' typical characteristic not to use psychological defense without any necessity, own uniqueness acceptance; for them it is not typical to change own opinion for general standards. At the same time, the decreased indices of spontaneity and self-acceptance show that boys still don't have well-formed realized self-concept and their self-actualization is mainly oriented towards own desires and needs realization in the future. It is also proved by ambiguous attitude to labor and the distinct index of emotionality, the manifestations of which are sensitivity, vulnerability and modesty. Lack of understanding the nature of a person and unexpressed sociability correspond with weak manifestation of such qualities as emotionality, trustfulness, desire to achieve compromise. It shows that boys don't have propensity for excessive close contacts with other people, lack of confidence in people.

Among more distinct characteristics of self-concept of girls we should mention orientation toward positive attitude to oneself, the manifestations of which are energy, single-mindedness, individuality, courage and directness. Moreover, girls-athletes value such quality as freedom. It corresponds with their high index of autonomy. It shows the tendency of self-support. Girls' propensity for living the present moment corresponds with such qualities as activity and kindness. It is also proved by orientation toward optimism, the manifestations of which are the following: high self-appraisal, buoyancy, kindness, selfconfidence. Girls'propensity for describing oneself with the help of such qualities as quick-wittedness, power of a personality, own opinion presence, activity corresponds with the tendency of positive self-attitude and optimism according to M. Kun and T. MacPartlend methodology. These results correspond with high indices of self-understanding, autosympathy and the need for cognition. They are typical for self-actualizing personality. At the same time, lack of the ability to accept different manifestations of a person's nature shows moderate demonstration of a person's communicative qualities and moderate commitment to family and interpersonal roles. However, the received results help to claim that in self-concept of girls the characteristics of self-actualization are presented more integrally and more distinctly, than among boys.

Thus, taking into account gender peculiarities of self-concept among students-athletes would help to individualize and effectively plan the process of their sportsmanship development at the stage of studying at a higher educational establishment.

\section{References}

1. P.D. Saville, S.R. Bray, Journal of Applied Sport Psychology, 28(1), 1-13 (2016). DOI: 10.1080/10413200.2015.1052890

2. S.A. Jackson, P.R. Thomas, H.W. Marsh, Ch.J. Smethurst, Journal of Applied Sport Psychology, 13(2), 129-153 (2001). DOI: 10.1080/104132001753149865

3. R.J. Schinke, N.B. Stambulova,G. Si, \& Z. Moore, International Journal of Sport and Exercise Psychology, 16(6), 622-639 (2018). doi:10.1080/1612197X.2017.1295557 
4. Ch.A. Villalon, S.B. Martin, Journal of Applied Sport Psychology, 32(1), $64-80$ (2020). DOI: 10.1080/10413200.2018.1549620

5. Ch.B. Thom, F. Guay, Ch. Trottier, Journal of Applied Sport Psychology (2020). DOI: 10.1080/10413200.2020.1808736

6. M. Audiffren, N. André, Journal of Sport and Health Science, 4, 30-46 (2015). doi:10.1016/j.jshs.2014.09.002

7. C. Englert, Frontiers in Psychology, 7, 314 (2016). doi:10.3389/fpsyg.2016.00314

8. W. Hofmann, B.J. Schmeiche, A.D. Baddeley, Trends in Cognitive Sciences, 16, 174-180 (2012). doi:10.1016/j.tics.2012.01.006

9. A.S. Kuznetsov, Z.M. Kuznetsova, Russian Journal of Physical Education and Sport, 14(4), 5-7 (2019). DOI: 10.14526/2070-4798-2019-14-4-5-7 